\title{
Fixed point results for modified weak and rational $\alpha-\psi$-contractions in ordered 2-metric spaces
}

\author{
Shahin Fathollahi', Nawab Hussain ${ }^{2}$ and Liaqat A Khan² ${ }^{2 *}$
}

${ }^{\text {*} C o r r e s p o n d e n c e: ~}$ Ikhan@kau.edu.sa 2Department of Mathematics, King Abdulaziz University, P.O. Box 80203 Jeddah, 21589, Saudi Arabia Full list of author information is available at the end of the article

\begin{abstract}
We first introduce the concept of a triangular $2-\alpha-\eta$-admissible mapping which extends the notion of $\alpha$-admissible mapping with respect to $\eta$ to 2 -metric spaces. Next, we introduce the concepts of modified weak and modified rational $\alpha-\psi$-contractions and establish the existence and uniqueness of fixed points for such mappings in complete 2-metric spaces. As an application of the obtained results, we prove some fixed point results in partially ordered 2-metric spaces. The presented theorems generalize and improve certain existing results in the literature and provide main results in Dung and Hang (Fixed Point Theory Appl. 2013:161, 2013) as corollaries. Moreover, some examples and an application to integral equations are provided to illustrate the usability of the obtained results.
\end{abstract}

MSC: $46 \mathrm{~N} 40 ; 47 \mathrm{H} 10 ; 54 \mathrm{H} 25 ; 46 \mathrm{~T} 99$

Keywords: modified weak $\alpha-\eta$-contractions; modified rational $\alpha-\eta$ - $\psi$-contractions; triangular 2- $\alpha-\eta$-admissible map; partially ordered 2-metric space

\section{Introduction and preliminaries}

There exist many generalizations of the concept of metric spaces in the literature $(d(x, y) \in$ $\mathbb{R}_{+} ; d(x, y) \in K, K$ a cone in an ordered Banach space; 2-metric spaces; probabilistic metric spaces; G-metric spaces etc.; see, for example, [1-9]). The notion of 2-metric was introduced by Gähler in [10]. Note that a 2-metric is not a continuous function of its variables, whereas an ordinary metric is. This led Dhage to introduce the notion of $D$-metric in [11]. In $[12,13]$ Mustafa and Sims introduced the notion of $G$-metric to overcome flaws of a $D$-metric. After that, many fixed point theorems on $G$-metric spaces have been proved (see [14] and the references therein). The authors in [15] and [16] noticed that in several situations fixed point results in G-metric spaces can be in fact deduced from fixed point theorems in metric or quasi-metric spaces. It has also been shown by various authors that in several cases the fixed point results in cone metric spaces can be obtained by reducing them to their standard metric counterparts; for example, see [17-19]. It is worth to note that in the above generalizations, a 2-metric space was not known to be topologically equivalent to an ordinary metric.

We recollect some essential notations, required definitions and primary results coherent with the literature.

(02014 Fathollahi et al.: licensee Springer. This is an Open Access article distributed under the terms of the Creative Commons Attribution License (http://creativecommons.org/licenses/by/2.0), which permits unrestricted use, distribution, and reproduction in any medium, provided the original work is properly cited. 
Definition 1.1 [10] Let $X$ be a non-empty set and let $d: X \times X \times X \rightarrow \mathbb{R}^{+}$be a mapping satisfying the following assertions:

(d1) For every pair of distinct points $x, y \in X$, there exists a point $z \in X$ such that $d(x, y, z) \neq 0$

(d2) If at least two of three points $x, y, z$ are the same, then $d(x, y, z)=0$;

(d3) The symmetry:

$$
d(x, y, z)=d(x, z, y)=d(y, x, z)=d(y, z, x)=d(z, x, y)=d(z, y, x)
$$

for all $x, y, z \in X$;

(d4) The rectangle inequality: $d(x, y, z) \leq d(x, y, t)+d(y, z, t)+d(z, x, t)$ for all $x, y, z, t \in X$.

Then $d$ is called a 2-metric on $X$ and $(X, d)$ is called a 2-metric space which will be sometimes denoted by $X$ if there is no confusion. Every member $x \in X$ is called a point in $X$.

Definition 1.2 [10] Let $(X, d)$ be a 2-metric space and $a, b \in X, r \geq 0$. The set

$$
B(a, b, r)=\{x \in X: d(a, b, x)<r\}
$$

is called a 2-ball centered at $a$ and $b$ with radius $r$. The topology generated by the collection of all 2-balls as a subbase is called a 2-metric topology on $X$.

Definition 1.3 [20] Let $\left\{x_{n}\right\}$ be a sequence in a 2-metric space $(X, d)$.

- $\left\{x_{n}\right\}$ is said to be convergent to $x$ in $(X, d)$, written $\lim _{n \rightarrow \infty} x_{n}=x$, if for all $a \in X$, $\lim _{n \rightarrow \infty} d\left(x_{n}, x, a\right)=0$;

- $\left\{x_{n}\right\}$ is said to be Cauchy in $X$ if for all $a \in X, \lim _{n, m \rightarrow \infty} d\left(x_{n}, x_{m}, a\right)=0$, that is, for each $\epsilon>0$, there exists $n_{0}$ such that $d\left(x_{n}, x_{m}, a\right)<\epsilon$ for all $n, m \geq n_{0}$ and $a \in X$;

- $(X, d)$ is said to be complete if every Cauchy sequence is a convergent sequence.

Definition 1.4 [20] A 2-metric space $(X, d)$ is said to be compact if every sequence in $\mathrm{X}$ has a convergent subsequence.

Lemma 1.1 [20] Every 2-metric space is a $T_{1}$-space.

Lemma $1.2[20] \lim _{n \rightarrow \infty} x_{n}=x$ in a 2-metric space $(X, d)$ if and only if $\lim _{n \rightarrow \infty} x_{n}=x$ in the 2-metric topological space $X$.

Lemma 1.3 [20] If $T: X \rightarrow Y$ is a continuous map from a 2-metric space $X$ to a 2-metric space $Y$, then $\lim _{n \rightarrow \infty} x_{n}=x$ in $X$ implies $\lim _{n \rightarrow \infty} T x_{n}=T x$ in $Y$.

It is straightforward from Definitions 1.1-1.3 that every 2-metric is non-negative and every 2-metric space contains at least three distinct points. A 2-metric $d(x, y, z)$ is sequentially continuous in one argument; moreover, if a 2-metric $d(x, y, z)$ is sequentially continuous in two arguments, then it is sequentially continuous in all three arguments (see [21]). A convergent sequence in a 2-metric space need not be a Cauchy sequence (see [21]). In a 2-metric space $(X, d)$ every convergent sequence is a Cauchy sequence if $d$ is continuous 
(see [21]). There exists a 2-metric space $(X, d)$ such that every convergent sequence is a Cauchy sequence but $d$ is not continuous (see [21]).

Chatterjea in [22] introduced the notion of C-contraction as follows.

Definition 1.5 Let $(X, d)$ be a metric space and $T: X \rightarrow X$ be a map. Then $T$ is called a C-contraction if there exists $a \in[0,1)$ such that for all $x, y \in X$,

$$
d(T x, T y) \leq \frac{a}{2}[d(x, T y)+d(y, T x)] .
$$

This notion was generalized to a weak C-contraction by Choudhury in [23].

Definition 1.6 Let $(X, d)$ be a metric space and $T: X \rightarrow X$ be a map. Then $T$ is called a weak $C$-contraction if there exists $\psi:[0, \infty)^{2} \rightarrow[0, \infty)$ which is continuous, and $\psi(s, t)=$ 0 if and only if $s=t=0$ such that

$$
d(T x, T y) \leq \frac{1}{2}[d(x, T y)+d(y, T x)]-\psi(d(x, T y), d(y, T x))
$$

for all $x, y \in X$.

Samet et al. [24] defined the notion of $\alpha$-admissible mappings as follows.

Definition 1.7 Let $T$ be a self-mapping on $X$ and $\alpha: X \times X \rightarrow[0,+\infty)$ be a function. We say that $T$ is an $\alpha$-admissible mapping if

$$
x, y \in X, \quad \alpha(x, y) \geq 1 \quad \Longrightarrow \quad \alpha(T x, T y) \geq 1 .
$$

In [24] the authors considered the family $\Psi$ of non-decreasing functions $\psi:[0,+\infty) \rightarrow$ $[0,+\infty)$ such that $\sum_{n=1}^{+\infty} \psi^{n}(t)<+\infty$ for each $t>0$, where $\psi^{n}$ is the $n$th iterate of $\psi$, and they gave the following theorem.

Theorem 1.1 Let $(X, d)$ be a complete metric space and $T$ be an $\alpha$-admissible mapping. Assume that

$$
\alpha(x, y) d(T x, T y) \leq \psi(d(x, y))
$$

for all $x, y \in X$, where $\psi \in \Psi$. Also, suppose that the following assertions hold:

(i) there exists $x_{0} \in X$ such that $\alpha\left(x_{0}, T x_{0}\right) \geq 1$;

(ii) either $T$ is continuous or for any sequence $\left\{x_{n}\right\}$ in $X$ with $\alpha\left(x_{n}, x_{n+1}\right) \geq 1$ for all $n \in \mathbb{N} \cup\{0\}$ and $x_{n} \rightarrow x$ as $n \rightarrow+\infty$, we have $\alpha\left(x_{n}, x\right) \geq 1$ for all $n \in \mathbb{N} \cup\{0\}$.

Then $T$ has a fixed point.

Salimi et al. [25] modified and generalized the notions of $\alpha-\psi$-contractive and $\alpha$ admissible mappings as follows.

Definition 1.8 [25] Let $T$ be a self-mapping on $X$ and $\alpha, \eta: X \times X \rightarrow[0,+\infty)$ be two functions. We say that $T$ is an $\alpha$-admissible mapping with respect to $\eta$ if

$$
x, y \in X, \quad \alpha(x, y) \geq \eta(x, y) \quad \Longrightarrow \quad \alpha(T x, T y) \geq \eta(T x, T y) .
$$


Note that if we take $\eta(x, y)=1$, then this definition reduces to Definition 1.7. Also, if we take $\alpha(x, y)=1$, then we say that $T$ is an $\eta$-subadmissible mapping.

The following result properly contains Theorem 1.1 and Theorems 2.3 and 2.4 of [26].

Theorem 1.2 [25] Let $(X, d)$ be a complete metric space and $T$ be an $\alpha$-admissible mapping. Assume that

$$
x, y \in X, \quad \alpha(x, y) \geq 1 \quad \Longrightarrow \quad d(T x, T y) \leq \psi(M(x, y)),
$$

where $\psi \in \Psi$ and

$$
M(x, y)=\max \left\{d(x, y), \frac{d(x, T x)+d(y, T y)}{2}, \frac{d(x, T y)+d(y, T x)}{2}\right\} .
$$

Also, suppose that the following assertions hold:

(i) there exists $x_{0} \in X$ such that $\alpha\left(x_{0}, T x_{0}\right) \geq 1$;

(ii) either $T$ is continuous or for any sequence $\left\{x_{n}\right\}$ in $X$ with $\alpha\left(x_{n}, x_{n+1}\right) \geq 1$ for all $n \in \mathbb{N} \cup\{0\}$ and $x_{n} \rightarrow x$ as $n \rightarrow+\infty$, we have $\alpha\left(x_{n}, x\right) \geq 1$ for all $n \in \mathbb{N} \cup\{0\}$.

Then $T$ has a fixed point.

Recently Karapinar et al. [27] introduced the notion of triangular $\alpha$-admissible mapping as follows.

Definition 1.9 [27] Let $T: X \rightarrow X$ and $\alpha: X \times X \rightarrow(-\infty,+\infty)$. We say that $T$ is a triangular $\alpha$-admissible mapping if

(T1) $\alpha(x, y) \geq 1$ implies $\alpha(T x, T y) \geq 1, x, y \in X$,

(T2) $\left\{\begin{array}{l}\alpha(x, z) \geq 1, \\ \alpha(z, y) \geq 1\end{array}\right.$ implies $\alpha(x, y) \geq 1$.

Motivated by the above-mentioned developments, we first introduce the concepts of $2-\alpha-\eta$-admissible mappings and weak and rational $\alpha-\eta-\psi$-contractions and establish the existence and uniqueness of fixed points for such mappings in complete 2-metric spaces. As an application of obtained results, we prove some fixed point theorems in partially ordered 2-metric spaces. The presented theorems generalize and improve many existing results in the literature. Moreover, some examples and an application to integral equations are provided to illustrate the usability of the proved results.

\section{Fixed point results for weak $\alpha-\eta$-C-contraction mappings}

Motivated by Karapinar et al. [27] and Salimi et al. [25], we introduce the following notion.

Definition 2.1 Let $(X, d)$ be a 2-metric space and $T: X \rightarrow X$ and $\alpha, \eta: X \times X \times X \rightarrow$ $[0,+\infty)$ be mappings. We say that $T$ is a triangular $2-\alpha-\eta$-admissible mapping if for all $a \in X$,

(T1) $\alpha(x, y, a) \geq \eta(x, y, a)$ implies $\alpha(T x, T y, a) \geq \eta(T x, T y, a), x, y \in X$,

(T2) $\left\{\begin{array}{l}\alpha(x, z, a) \geq \eta(x, z, a), \\ \alpha(z, y, a) \geq \eta(z, y, a)\end{array}\right.$ implies $\alpha(x, y, a) \geq \eta(x, y, a)$.

If we take $\eta(x, y, a)=1$, then we say that $T$ is a triangular 2- $\alpha$-admissible mapping. Also, if we take $\alpha(x, y, a)=1$, then we say that $T$ is a triangular $2-\eta$ - subadmissible mapping. 
Example 2.1 Let $X=[0, \infty)$. Define $T: X \rightarrow X$ and $\alpha, \eta: X \times X \times X \rightarrow[0,+\infty)$ by $T x=$ $\frac{1}{4} x$,

$$
\alpha(x, y, a)=\left\{\begin{array}{ll}
a^{2}+2 & \text { if } x, y \in[0,1], \\
0 & \text { otherwise }
\end{array} \text { and } \quad \eta(x, y, a)=a^{2}+1\right.
$$

Then $T$ is a triangular $2-\alpha-\eta$-admissible mapping.

Lemma 2.1 Let $(X, d)$ be a 2-metric space and $T: X \rightarrow X$ be a triangular 2- $\alpha-\eta$-admissible mapping. Assume that there exists $x_{0} \in X$ such that $\alpha\left(x_{0}, T x_{0}, a\right) \geq \eta\left(x_{0}, T x_{0}, a\right)$ for all $a \in X$. Define the sequence $\left\{x_{n}\right\}$ by $x_{n}=T^{n} x_{0}$. Then

$$
\alpha\left(x_{m}, x_{n}, a\right) \geq \eta\left(x_{m}, x_{n}, a\right) \text { for all } m, n \in \mathbb{N} \text { with } m<n \text { and for all } a \in X \text {. }
$$

Proof Since there exists $x_{0} \in X$ such that $\alpha\left(x_{0}, T x_{0}, a\right) \geq \eta\left(x_{0}, T x_{0}, a\right)$, then from (T1) we deduce that

$$
\alpha\left(x_{1}, x_{2}, a\right)=\alpha\left(T x_{0}, T^{2} x_{0}, a\right) \geq \eta\left(T x_{0}, T^{2} x_{0}, a\right)=\eta\left(x_{1}, x_{2}, a\right) .
$$

By continuing this process, we get

$$
\alpha\left(x_{n}, x_{n+1}, a\right) \geq \eta\left(x_{n}, x_{n+1}, a\right) \quad \text { for all } n \in \mathbb{N} \cup\{0\} .
$$

Suppose that $m<n$. Since

$$
\left\{\begin{array}{l}
\alpha\left(x_{m}, x_{m+1}, a\right) \geq \eta\left(x_{m}, x_{m+1}, a\right), \\
\alpha\left(x_{m+1}, x_{m+2}, a\right) \geq \eta\left(x_{m+1}, x_{m+2}, a\right)
\end{array}\right.
$$

then from (T2) we have $\alpha\left(x_{m}, x_{m+2}, a\right) \geq \eta\left(x_{m}, x_{m+2}, a\right)$.

Again, since

$$
\left\{\begin{array}{l}
\alpha\left(x_{m}, x_{m+2}, a\right) \geq \eta\left(x_{m}, x_{m+2}, a\right), \\
\alpha\left(x_{m+2}, x_{m+3}, a\right) \geq \eta\left(x_{m+2}, x_{m+3}, a\right),
\end{array}\right.
$$

then we deduce $\alpha\left(x_{m}, x_{m+3}, a\right) \geq \eta\left(x_{m}, x_{m+3}, a\right)$.

By continuing this process, we get $\alpha\left(x_{m}, x_{n}, a\right) \geq \eta\left(x_{m}, x_{n}, a\right)$ as required.

Definition 2.2 Let $(X, d)$ be a 2-metric space. Let $\alpha, \eta: X \times X \times X \rightarrow[0, \infty)$ and $T: X \rightarrow X$. We say that $T$ is $2-\alpha-\eta$-continuous on $(X, d)$ if

$$
\begin{aligned}
& x_{n} \rightarrow x \quad \text { as } n \rightarrow \infty, \\
& \alpha\left(x_{n}, x_{n+1}, a\right) \geq \eta\left(x_{n}, x_{n+1}, a\right) \quad \text { for all } n \in \mathbb{N} \text { and } a \in X \Longrightarrow T x_{n} \rightarrow T x .
\end{aligned}
$$

If we take $\eta(x, y, a)=1$, then we say that $T$ is a 2 - $\alpha$-continuous mapping. Also, if we take $\alpha(x, y, a)=1$, then we say that $T$ is a $2-\eta$-continuous mapping. 
Example 2.2 Let $X=[0, \infty)$ and $d(x, y, a)=\min \{|x-y|,|y-a|,|x-a|\}$. Assume that $T$ : $X \rightarrow X$ and $\alpha, \eta: X^{3} \rightarrow[0,+\infty)$ are defined by

$$
\begin{aligned}
& T x= \begin{cases}x^{2} & \text { if } x \in[0,1], \\
\ln x+2 & \text { if } x \in(1, \infty),\end{cases} \\
& \alpha(x, y, a)=\left\{\begin{array}{ll}
1 & \text { if } x, y \in[0,1], \\
0 & \text { otherwise }
\end{array} \text { and } \eta(x, y, a)=1 .\right.
\end{aligned}
$$

Clearly, $T$ is not continuous, but $T$ is $2-\alpha-\eta$-continuous on $(X, d)$. Indeed, if $x_{n} \rightarrow x$ as $n \rightarrow$ $\infty$ and $\alpha\left(x_{n}, x_{n+1}, a\right) \geq \eta\left(x_{n}, x_{n+1}, a\right)=1$, then $x_{n} \in[0,1]$ and so $\lim _{n \rightarrow \infty} T x_{n}=\lim _{n \rightarrow \infty} x_{n}^{2}=$ $x^{2}=T x$.

Denote with $\Psi$ the family of continuous functions $\psi:[0, \infty)^{2} \rightarrow[0, \infty)$ such that $\psi(s, t)=0$ if and only if $s=t=0$.

We introduce the following notions as a modification of the approach in [25].

Definition 2.3 Let $(X, d)$ be a 2-metric space and $T: X \rightarrow X, \alpha, \eta: X \times X \times X \rightarrow[0,+\infty)$ be three mappings.

- We say that $T$ is a weak $\alpha-\eta$-C-contraction mapping if

$$
\begin{aligned}
x, y & \in X, \quad \alpha(x, y, a) \geq \eta(x, y, a) \\
\Longrightarrow \quad d(T x, T y, a) & \leq \frac{1}{2}[d(x, T y, a)+d(y, T x, a)]-\psi(d(x, T y, a), d(y, T x, a))
\end{aligned}
$$

for all $a \in X$, where $\psi \in \Psi$.

- We say that $T$ is a modified weak $\alpha$-C-contraction mapping if

$$
\begin{aligned}
x, y & \in X, \quad \alpha(x, y, a) \geq 1 \\
\Longrightarrow & d(T x, T y, a) \leq \frac{1}{2}[d(x, T y, a)+d(y, T x, a)]-\psi(d(x, T y, a), d(y, T x, a))
\end{aligned}
$$

for all $a \in X$, where $\psi \in \Psi$.

- We say that $T$ is a modified weak $\eta$-C-contraction mapping if

$$
\begin{aligned}
x, y & \in X, \quad \eta(x, y, a) \leq 1 \\
\Longrightarrow \quad d(T x, T y, a) & \leq \frac{1}{2}[d(x, T y, a)+d(y, T x, a)]-\psi(d(x, T y, a), d(y, T x, a))
\end{aligned}
$$

for all $a \in X$, where $\psi \in \Psi$.

- We say that $T$ is a weak $\alpha$-C-contraction mapping of type (I) if

$$
\alpha(x, y, a) d(T x, T y, a) \leq \frac{1}{2}[d(x, T y, a)+d(y, T x, a)]-\psi(d(x, T y, a), d(y, T x, a))
$$

for all $x, y, a \in X$, where $\psi \in \Psi$. 
- We say that $T$ is a weak $\eta$-C-contraction mapping of type (I) if

$$
d(T x, T y, a) \leq \frac{\eta(x, y, a)}{2}[d(x, T y, a)+d(y, T x, a)]-\psi(d(x, T y, a), d(y, T x, a))
$$

for all $x, y, a \in X$, where $\psi \in \Psi$.

- We say that $T$ is a weak $\alpha$-C-contraction mapping of type (II) if

$$
(\alpha(x, y, a)+\ell)^{d(T x, T y, a)} \leq(1+\ell)^{\frac{1}{2}[d(x, T y, a)+d(y, T x, a)]-\psi(d(x, T y, a), d(y, T x, a))}
$$

for all $x, y, a \in X$, where $\psi \in \Psi$ and $\ell>0$.

- We say that $T$ is a weak $\eta$-C-contraction mapping of type (II) if

$$
(1+\ell)^{d(T x, T y, a)} \leq(\eta(x, y, a)+\ell)^{\frac{1}{2}[d(x, T y, a)+d(y, T x, a)]-\psi(d(x, T y, a), d(y, T x, a))}
$$

for all $x, y, a \in X, \ell>0$ and $\psi \in \Psi$.

Now we are ready to state and prove our first main result of this section.

Theorem 2.1 Let $(X, d)$ be a complete 2-metric space. Assume that $T: X \rightarrow X$ is a weak $\alpha-\eta$-C-contraction mapping satisfying the following assertions:

(i) $T$ is a triangular $2-\alpha-\eta$-admissible mapping;

(ii) there exists $x_{0}$ in $X$ such that $\alpha\left(x_{0}, T x_{0}, a\right) \geq \eta\left(x_{0}, T x_{0}, a\right)$ for all $a \in X$;

(iii) $T$ is continuous or 2- $\alpha-\eta$-continuous; or

(iv) if $\left\{x_{n}\right\}$ is a sequence in $X$ such that $\alpha\left(x_{n}, x_{n+1}, a\right) \geq \eta\left(x_{n}, x_{n+1}, a\right)$ for all $a \in X$ and $x_{n} \rightarrow x$ as $n \rightarrow \infty$, then $\alpha\left(x_{n}, x, a\right) \geq \eta\left(x_{n}, x, a\right)$ for all $n \in \mathbb{N}$ and all $a \in X$.

Then $T$ has a fixed point.

Proof Let $x_{0} \in X$ such that $\alpha\left(x_{0}, T x_{0}, a\right) \geq \eta\left(x_{0}, T x_{0}, a\right)$ for all $a \in X$. Define a sequence $\left\{x_{n}\right\}$ by $x_{n}=T^{n} x_{0}$ for all $n \in \mathbb{N}$. Now, since $T$ is a triangular 2- $\alpha-\eta$-admissible mapping, so by Lemma 2.1 we have

$$
\alpha\left(x_{m}, x_{n}, a\right) \geq \eta\left(x_{m}, x_{n}, a\right) \quad \text { for all } m, n \in \mathbb{N} \text { with } m<n \text { and for all } a \in X \text {. }
$$

From (2.2) we deduce

$$
\begin{aligned}
d\left(x_{n+1}, x_{n}, a\right) & =d\left(T x_{n}, T x_{n-1}, a\right) \\
& \leq \frac{1}{2}\left[d\left(x_{n}, T x_{n-1}, a\right)+d\left(x_{n-1}, T x_{n}, a\right)\right]-\psi\left(d\left(x_{n}, T x_{n-1}, a\right), d\left(x_{n-1}, T x_{n}, a\right)\right) \\
& =\frac{1}{2}\left[d\left(x_{n}, x_{n}, a\right)+d\left(x_{n-1}, x_{n+1}, a\right)\right]-\psi\left(d\left(x_{n}, x_{n}, a\right), d\left(x_{n-1}, x_{n+1}, a\right)\right) \\
& =\frac{1}{2} d\left(x_{n-1}, x_{n+1}, a\right)-\psi\left(0, d\left(x_{n-1}, x_{n+1}, a\right)\right) \\
& \leq \frac{1}{2} d\left(x_{n-1}, x_{n+1}, a\right)
\end{aligned}
$$

for all $a \in X$. By taking $a=x_{n-1}$ in (2.4), we get $d\left(x_{n+1}, x_{n}, x_{n-1}\right) \leq 0$, i.e.,

$$
d\left(x_{n+1}, x_{n}, x_{n-1}\right)=0,
$$


and so by (2.4) and (2.5) we have

$$
\begin{aligned}
d\left(x_{n+1}, x_{n}, a\right) & \leq \frac{1}{2} d\left(x_{n-1}, x_{n+1}, a\right) \\
& \leq \frac{1}{2}\left[d\left(x_{n-1}, x_{n}, a\right)+d\left(x_{n}, x_{n+1}, a\right)+d\left(x_{n-1}, x_{n}, x_{n+1}\right)\right] \\
& \leq \frac{1}{2}\left[d\left(x_{n-1}, x_{n}, a\right)+d\left(x_{n}, x_{n+1}, a\right)\right],
\end{aligned}
$$

which implies

$$
d\left(x_{n+1}, x_{n}, a\right) \leq d\left(x_{n-1}, x_{n}, a\right) .
$$

Hence, the sequence $\left\{d\left(x_{n+1}, x_{n}, a\right)\right\}$ is decreasing in $\mathbb{R}_{+}$and so it is convergent to $r \in \mathbb{R}_{+}$, i.e., $\lim _{n \rightarrow \infty} d\left(x_{n+1}, x_{n}, a\right)=r$. Taking limit in (2.6) we get

$$
r \leq \frac{1}{2} \lim _{n \rightarrow \infty} d\left(x_{n-1}, x_{n+1}, a\right) \leq \frac{1}{2}(r+r)=r
$$

and then

$$
\lim _{n \rightarrow \infty} d\left(x_{n-1}, x_{n+1}, a\right)=2 r .
$$

By taking limit as $n \rightarrow \infty$ in (2.4) and applying (2.8), we get

$$
r \leq \frac{1}{2}(2 r)-\psi(0,2 r) \leq r
$$

This implies $\psi(0,2 r)=0$, i.e., $r=0$. Hence,

$$
\lim _{n \rightarrow \infty} d\left(x_{n+1}, x_{n}, a\right)=0 .
$$

If $d\left(x_{n-1}, x_{n}, a\right)=0$, then by (2.7) we have $d\left(x_{n+1}, x_{n}, a\right)=0$. Since $d\left(x_{0}, x_{1}, x_{0}\right)=0$, we have $d\left(x_{n}, x_{n+1}, x_{0}\right)=0$ for all $n \in \mathbb{N}$. Since $d\left(x_{m-1}, x_{m}, x_{m}\right)=0$, we have

$$
d\left(x_{n}, x_{n+1}, x_{m}\right)=0
$$

for all $n \geq m-1$. For $0 \leq n<m-1$, noting that $m-1 \geq n+1$, from (2.10) we have

$$
d\left(x_{m-1}, x_{m}, x_{n+1}\right)=d\left(x_{m-1}, x_{m}, x_{n}\right)=0,
$$

which implies

$$
\begin{aligned}
d\left(x_{n}, x_{n+1}, x_{m}\right) & \leq d\left(x_{n}, x_{n+1}, x_{m-1}\right)+d\left(x_{n+1}, x_{m}, x_{m-1}\right)+d\left(x_{m}, x_{n}, x_{m-1}\right) \\
& =d\left(x_{n}, x_{n+1}, x_{m-1}\right) .
\end{aligned}
$$

Now, since $d\left(x_{n}, x_{n+1}, x_{n+1}\right)=0$, from (2.11) we get

$$
d\left(x_{n}, x_{n+1}, x_{m}\right)=0
$$


for all $0 \leq n<m-1$. Hence, from (2.10) and (2.12) we have $d\left(x_{n}, x_{n+1}, x_{m}\right)=0$ for all $m, n \in \mathbb{N}$. Now, for all $i, j, k \in \mathbb{N}$ with $i<j$, we have $d\left(x_{j-1}, x_{j}, x_{i}\right)=d\left(x_{j-1}, x_{j}, x_{k}\right)=0$. Hence,

$$
\begin{aligned}
d\left(x_{i}, x_{j}, x_{k}\right) & \leq d\left(x_{i}, x_{j}, x_{j-1}\right)+d\left(x_{j}, x_{k}, x_{j-1}\right)+d\left(x_{k}, x_{i}, x_{j-1}\right) \\
& =d\left(x_{i}, x_{j-1}, x_{k}\right) \leq \cdots \leq d\left(x_{i}, x_{i}, x_{k}\right)=0 .
\end{aligned}
$$

That is, for all $i, j, k \in \mathbb{N}$, we have

$$
d\left(x_{i}, x_{j}, x_{k}\right)=0 .
$$

We now show that $\left\{x_{n}\right\}$ is a Cauchy sequence. Suppose to the contrary that $\left\{x_{n}\right\}$ is not a Cauchy sequence. Then there are $\varepsilon>0$ and sequences $\{m(k)\}$ and $\{n(k)\}$ such that for all positive integers $k$,

$$
n(k)>m(k)>k, \quad d\left(x_{n(k)}, x_{m(k)}, a\right) \geq \varepsilon \quad \text { and } \quad d\left(x_{n(k)-1}, x_{m(k)}, a\right)<\varepsilon .
$$

From (2.13) and (2.14) we deduce

$$
\begin{aligned}
\epsilon & \leq d\left(x_{n(k)}, x_{m(k)}, a\right) \\
& \leq d\left(x_{n(k)}, x_{n(k)-1}, a\right)+d\left(x_{n(k)-1}, x_{m(k)}, a\right)+d\left(x_{n(k)}, x_{m(k)}, x_{n(k)-1}\right) \\
& =d\left(x_{n(k)}, x_{n(k)-1}, a\right)+d\left(x_{n(k)-1}, x_{m(k)}, a\right) \\
& <d\left(x_{n(k)}, x_{n(k)-1}, a\right)+\epsilon .
\end{aligned}
$$

Taking limit as $k \rightarrow \infty$ in the above inequality and applying (2.9), we get

$$
\lim _{k \rightarrow \infty} d\left(x_{n(k)}, x_{m(k)}, a\right)=\lim _{k \rightarrow \infty} d\left(x_{n(k)-1}, x_{m(k)}, a\right)=\epsilon .
$$

Also by (2.13) we get

$$
\begin{aligned}
d\left(x_{m(k)}, x_{n(k)-1}, a\right) \leq & d\left(x_{m(k)}, x_{m(k)-1}, a\right)+d\left(x_{m(k)-1}, x_{n(k)-1}, a\right)+d\left(x_{m(k)}, x_{n(k)-1}, x_{m(k)-1}\right) \\
= & d\left(x_{m(k)}, x_{m(k)-1}, a\right)+d\left(x_{m(k)-1}, x_{n(k)-1}, a\right) \\
\leq & d\left(x_{m(k)}, x_{m(k)-1}, a\right)+d\left(x_{m(k)-1}, x_{n(k)}, a\right)+d\left(x_{n(k)-1}, x_{n(k)}, a\right) \\
& +d\left(x_{m(k)-1}, x_{n(k)-1}, x_{n(k)}\right) \\
= & d\left(x_{m(k)}, x_{m(k)-1}, a\right)+d\left(x_{m(k)-1}, x_{n(k)}, a\right)+d\left(x_{n(k)-1}, x_{n(k)}, a\right)
\end{aligned}
$$

and

$$
\begin{aligned}
d\left(x_{m(k)-1}, x_{n(k)}, a\right) & \leq d\left(x_{m(k)-1}, x_{m(k)}, a\right)+d\left(x_{n(k)}, x_{m(k)}, a\right)+d\left(x_{m(k)-1}, x_{n(k)}, x_{m(k)}\right) \\
& =d\left(x_{m(k)-1}, x_{m(k)}, a\right)+d\left(x_{n(k)}, x_{m(k)}, a\right) .
\end{aligned}
$$

By taking limit as $k \rightarrow \infty$ in (2.16) and (2.17) and applying (2.9) and (2.15), we have

$$
\lim _{k \rightarrow \infty} d\left(x_{m(k)-1}, x_{n(k)}, a\right)=\epsilon
$$


Now since $n(k)>m(k)$, then by (2.3) we have

$$
\alpha\left(x_{m(k)-1}, x_{n(k)-1}, a\right) \geq \eta\left(x_{m(k)-1}, x_{n(k)-1}, a\right)
$$

for all $a \in X$. So by (2.2) we get

$$
\begin{aligned}
\epsilon \leq & d\left(x_{m(k)}, x_{n(k)}, a\right)=d\left(T x_{m(k)-1}, T x_{n(k)-1}, a\right) \\
\leq & \frac{1}{2}\left[d\left(x_{m(k)-1}, T x_{n(k)-1}, a\right)+d\left(x_{n(k)-1}, T x_{m(k)-1}, a\right)\right] \\
& -\psi\left(d\left(x_{m(k)-1}, T x_{n(k)-1}, a\right), d\left(x_{n(k)-1}, T x_{m(k)-1}, a\right)\right) \\
= & \frac{1}{2}\left[d\left(x_{m(k)-1}, x_{n(k)}, a\right)+d\left(x_{n(k)-1}, x_{m(k)}, a\right)\right] \\
& -\psi\left(d\left(x_{m(k)-1}, x_{n(k)}, a\right), d\left(x_{n(k)-1}, x_{m(k)}, a\right)\right) .
\end{aligned}
$$

Taking limit as $k \rightarrow \infty$ in (2.19) and applying (2.15), (2.18) and the continuity of $\psi$, we deduce

$$
\epsilon \leq \frac{1}{2}[\epsilon+\epsilon]-\psi(\epsilon, \epsilon)=\epsilon-\psi(\epsilon, \epsilon) \leq \epsilon,
$$

and so $\psi(\epsilon, \epsilon)=0$. That is, $\epsilon=0$ which is a contradiction. Hence, $\left\{x_{n}\right\}$ is a Cauchy sequence. Now, since $(X, d)$ is a complete 2-metric space, then there exists $x^{*} \in X$ such that $\lim _{n \rightarrow \infty} x_{n}=x^{*}$. At first we assume that (iii) holds. That is, $T$ is continuous. Then

$$
x^{*}=\lim _{n \rightarrow \infty} x_{n+1}=\lim _{n \rightarrow \infty} T x_{n}=T x^{*} .
$$

That is, $x^{*}$ is a fixed point of $T$. If $T$ is $2-\alpha-\eta$-continuous on $X, x_{n} \rightarrow x^{*}$ as $n \rightarrow \infty$ and $\alpha\left(x_{n}, x_{n+1}, a\right) \geq \eta\left(x_{n}, x_{n+1}, a\right)$, then we have

$$
T x^{*}=\lim _{n \rightarrow \infty} T x_{n}=\lim _{n \rightarrow \infty} x_{n+1}=x^{*} .
$$

So $x^{*}$ is a fixed point of $T$. Next we assume that (iv) holds. That is, $\alpha\left(x_{n}, x^{*}, a\right) \geq \eta\left(x_{n}, x^{*}, a\right)$ for all $n \in \mathbb{N}$ and all $a \in X$. Then by (2.2) we get

$$
\begin{aligned}
d\left(x_{n+1}, T x^{*}, a\right) & =d\left(T x_{n}, T x^{*}, a\right) \\
& \leq \frac{1}{2}\left[d\left(x_{n}, T x^{*}, a\right)+d\left(x^{*}, T x_{n}, a\right)\right]-\psi\left(d\left(x_{n}, T x^{*}, a\right), d\left(x^{*}, T x_{n}, a\right)\right) \\
& =\frac{1}{2}\left[d\left(x_{n}, T x^{*}, a\right)+d\left(x^{*}, x_{n+1}, a\right)\right]-\psi\left(d\left(x_{n}, T x^{*}, a\right), d\left(x^{*}, x_{n+1}, a\right)\right) .
\end{aligned}
$$

Taking limit as $n \rightarrow \infty$ in the above inequality, we get

$$
\begin{aligned}
d\left(x^{*}, T x^{*}, a\right) & \leq \frac{1}{2}\left[d\left(x^{*}, T x^{*}, a\right)+d\left(x^{*}, x^{*}, a\right)\right]-\psi\left(d\left(x^{*}, T x^{*}, a\right), d\left(x^{*}, x^{*}, a\right)\right) \\
& \leq \frac{1}{2} d\left(x^{*}, T x^{*}, a\right)-\psi\left(d\left(x^{*}, T x^{*}, a\right), 0\right) \\
& \leq \frac{1}{2} d\left(x^{*}, T x^{*}, a\right)
\end{aligned}
$$

which implies $d\left(x^{*}, T x^{*}, a\right)=0$, i.e., $x^{*}=T x^{*}$. 
By taking $\eta(x, y, a)=1$ in Theorem 2.1, we have the following corollary.

Corollary 2.1 Let $(X, d)$ be a complete 2 -metric space. Assume that $T: X \rightarrow X$ is a modified weak $\alpha-C$-contraction mapping satisfying the following assertions:

(i) $T$ is a triangular 2- $\alpha$-admissible mapping;

(ii) there exists $x_{0}$ in $X$ such that $\alpha\left(x_{0}, T x_{0}, a\right) \geq 1$ for all $a \in X$;

(iii) $T$ is continuous or 2- $\alpha$-continuous; or

(iv) if $\left\{x_{n}\right\}$ is a sequence in $X$ such that $\alpha\left(x_{n}, x_{n+1}, a\right) \geq 1$ for all $a \in X$ and $x_{n} \rightarrow x$ as $n \rightarrow \infty$, then $\alpha\left(x_{n}, x, a\right) \geq 1$ for all $n \in \mathbb{N}$ and all $a \in X$.

Then $T$ has a fixed point.

Example 2.3 Let $X=[0, \infty)$. We define a 2-metric $d$ on $X$ by

$$
d(x, y, a)=\min \{|x-y|,|y-a|,|x-a|\} .
$$

Clearly, $(X, d)$ is a complete 2 -metric space. Define $T: X \rightarrow X, \psi:[0, \infty)^{2} \rightarrow[0, \infty)$ and $\alpha: X \times X \times X \rightarrow[0, \infty)$ by

$$
T x=\left\{\begin{array}{ll}
\frac{\pi}{6} & \text { if } x \in[0,1], \\
x^{3}+(1+x)^{x} & \text { if } x \in(1,10], \\
\ln x+\sin x+1 & \text { if } x \in[10,15), \\
x^{2}+x+1 & \text { if } x \in[15, \infty),
\end{array} \quad \psi(s, t)=\frac{s+t}{4}\right.
$$

and

$$
\alpha(x, y, a)= \begin{cases}1 & \text { if } x, y \in[0,1] \\ \frac{1}{2} & \text { otherwise. }\end{cases}
$$

Now, we prove that all the hypotheses of Corollary 2.1 (Theorem 2.1) are satisfied and hence $T$ has a fixed point.

Proof Let $x, y, a \in X$, if $\alpha(x, y, a) \geq 1$, then $x, y \in[0,1]$. On the other hand, for all $w \in[0,1]$, we have $T w \leq 1$. Hence $\alpha(T x, T y, a) \geq 1$ for all $a \in X$. This implies that $T$ is a 2 - $\alpha$-admissible mapping. Clearly, $\alpha(0, T 0, a) \geq 1$ for all $a \in X$. Now, if $\left\{x_{n}\right\}$ is a sequence in $X$ such that $\alpha\left(x_{n}, x_{n+1}, a\right) \geq 1$ for all $n \in \mathbb{N} \cup\{0\}$ and $a \in X$ and $x_{n} \rightarrow x$ as $n \rightarrow+\infty$, then $\left\{x_{n}\right\} \subseteq[0,1]$ and hence $x \in[0,1]$. This implies that $\alpha\left(x_{n}, x, a\right) \geq 1$ for all $n \in \mathbb{N} \cup\{0\}$ and all $a \in X$.

Let $\alpha(x, y, a) \geq 1$. Then $x, y \in[0,1]$ and hence,

$$
\begin{aligned}
d(T x, T y, a) & =0 \leq \frac{1}{2}[d(x, T y, a)+d(y, T x, a)] \\
& =\frac{1}{2}[d(x, T y, a)+d(y, T x, a)]-\psi(d(x, T y, a), d(y, T x, a)) .
\end{aligned}
$$

That is,

$$
\begin{aligned}
& \alpha(x, y, a) \geq 1 \\
& \quad \Longrightarrow \quad d(T x, T y, a) \leq \frac{1}{2}[d(x, T y, a)+d(y, T x, a)]-\psi(d(x, T y, a), d(y, T x, a))
\end{aligned}
$$


for all $a \in X$. Hence, $T$ is a modified weak $\alpha$-C-contraction mapping. Then all the hypotheses of Corollary 2.1 (Theorem 2.1) are satisfied and hence $T$ has a fixed point.

By taking $\alpha(x, y, a)=1$ in Theorem 2.1, we have the following corollary.

Corollary 2.2 Let $(X, d)$ be a complete 2-metric space. Assume that $T: X \rightarrow X$ is a modified weak $\eta$-C-contraction mapping satisfying the following assertions:

(i) $T$ is a triangular 2- $\eta$-subadmissible mapping;

(ii) there exists $x_{0}$ in $X$ such that $\eta\left(x_{0}, T x_{0}, a\right) \leq 1$ for all $a \in X$;

(iii) $T$ is continuous or 2- $\eta$-continuous; or

(iv) if $\left\{x_{n}\right\}$ is a sequence in $X$ such that $\eta\left(x_{n}, x_{n+1}, a\right) \leq 1$ for all $a \in X$ and $x_{n} \rightarrow x$ as $n \rightarrow \infty$, then $\eta\left(x_{n}, x, a\right) \leq 1$ for all $n \in \mathbb{N}$ and all $a \in X$.

Then $T$ has a fixed point.

Example 2.4 Let $X, d$ be as in Example 2.3. Define $T: X \rightarrow X, \psi:[0, \infty)^{2} \rightarrow[0, \infty)$ and $\eta: X \times X \times X \rightarrow[0, \infty)$ by

$$
T x=\left\{\begin{array}{ll}
\frac{e}{4} & \text { if } x \in[0,1], \\
x^{2}+1 & \text { if } x \in(1,20], \\
\frac{1}{x^{2}+1}+3 x & \text { if } x \in[20,50), \\
\sqrt{x^{5}+1} & \text { if } x \in[50, \infty),
\end{array} \quad \psi(s, t)=\frac{s+t}{8}\right.
$$

and

$$
\eta(x, y, a)= \begin{cases}0 & \text { if } x, y \in[0,1] \\ 10 & \text { otherwise }\end{cases}
$$

Now, we prove that all the hypotheses of Corollary 2.2 (Theorem 2.1) are satisfied and hence $T$ has a fixed point.

Proof Let $x, y, a \in X$, if $\eta(x, y, a) \leq 1$, then $x, y \in[0,1]$. On the other hand, for all $w \in[0,1]$, we have $T w \leq 1$. Hence $\eta(T x, T y, a) \leq 1$ for all $a \in X$. This implies that $T$ is a $2-\eta$-admissible mapping. Clearly, $\eta(0, T 0, a) \leq 1$ for all $a \in X$.

Now, if $\left\{x_{n}\right\}$ is a sequence in $X$ such that $\eta\left(x_{n}, x_{n+1}, a\right) \leq 1$ for all $n \in \mathbb{N} \cup\{0\}$ and $a \in X$ and $x_{n} \rightarrow x$ as $n \rightarrow+\infty$, then $\left\{x_{n}\right\} \subseteq[0,1]$ and hence $x \in[0,1]$. This implies that $\eta\left(x_{n}, x, a\right) \leq 1$ for all $n \in \mathbb{N} \cup\{0\}$ and all $a \in X$.

If $\eta(x, y, a) \leq 1$, then $x, y \in[0,1]$ and so

$$
\begin{aligned}
d(T x, T y, a) & =0 \leq \frac{3}{8}[d(x, T y, a)+d(y, T x, a)] \\
& =\frac{1}{2}[d(x, T y, a)+d(y, T x, a)]-\psi(d(x, T y, a), d(y, T x, a)) .
\end{aligned}
$$

That is,

$$
\begin{aligned}
& \eta(x, y, a) \leq 1 \\
& \quad \Longrightarrow \quad d(T x, T y, a) \leq \frac{1}{2}[d(x, T y, a)+d(y, T x, a)]-\psi(d(x, T y, a), d(y, T x, a))
\end{aligned}
$$


for all $a \in X$. Hence, $T$ is a modified weak $\eta$-C-contraction mapping. Then all the hypotheses of Corollary 2.2 (Theorem 2.1) are satisfied and hence $T$ has a fixed point.

Corollary 2.3 Let $(X, d)$ be a complete 2-metric space. Assume that $T: X \rightarrow X$ is a weak $\alpha$ $C$-contraction mapping of type (I) or a weak $\alpha$-C-contraction mapping of type (II) satisfying the following assertions:

(i) $T$ is a triangular 2- $\alpha$-admissible mapping;

(ii) there exists $x_{0}$ in $X$ such that $\alpha\left(x_{0}, T x_{0}, a\right) \geq 1$ for all $a \in X$;

(iii) $T$ is continuous or 2- $\alpha$-continuous; or

(iv) if $\left\{x_{n}\right\}$ is a sequence in $X$ such that $\alpha\left(x_{n}, x_{n+1}, a\right) \geq 1$ for all $a \in X$ and $x_{n} \rightarrow x$ as $n \rightarrow \infty$, then $\alpha\left(x_{n}, x, a\right) \geq 1$ for all $n \in \mathbb{N}$ and all $a \in X$.

Then $T$ has a fixed point.

Corollary 2.4 Let $(X, d)$ be a complete 2-metric space. Assume that $T: X \rightarrow X$ is a weak $\eta$-C-contraction mapping of type (I) or weak $\alpha$-C-contraction mapping of type (II) satisfying the following assertions:

(i) $T$ is a triangular 2- $\eta$-admissible mapping;

(ii) there exists $x_{0}$ in $X$ such that $\eta\left(x_{0}, T x_{0}, a\right) \leq 1$ for all $a \in X$;

(iii) $T$ is continuous or 2- $\eta$-continuous; or

(iv) if $\left\{x_{n}\right\}$ is a sequence in $X$ such that $\eta\left(x_{n}, x_{n+1}, a\right) \leq 1$ for all $a \in X$ and $x_{n} \rightarrow x$ as $n \rightarrow \infty$, then $\eta\left(x_{n}, x, a\right) \leq 1$ for all $n \in \mathbb{N}$ and all $a \in X$.

Then $T$ has a fixed point.

(A) For all $x, y \in X$, where $\alpha(x, y, a)<\eta(x, y, a)$ and $\alpha(y, x, a)<\eta(y, x, a)$ for all $a \in X$, there exists $z \in X$ such that $\alpha(x, z, a) \geq \eta(x, z, a)$ or $\alpha(z, x, a) \geq \eta(z, x, a)$ and $\alpha(y, z, a) \geq \eta(y, z, a)$ or $\alpha(z, y, a) \geq \eta(z, y, a)$ for all $a \in X$.

Theorem 2.2 Adding condition (A) to the hypotheses of Theorem 2.1 (resp. Corollary 2.1, 2.2, 2.3 and 2.4), we obtain the uniqueness of the fixed point of $T$.

Proof Assume that $x^{*}$ and $y^{*}$ are two fixed points of $T$. We consider to following cases.

Case 1: Let $\alpha\left(x^{*}, y^{*}, a\right) \geq \eta\left(x^{*}, y^{*}, a\right)$ or $\alpha\left(y^{*}, x^{*}, a\right) \geq \eta\left(y^{*}, x^{*}, a\right)$ for all $a \in X$. Then from (2.2) we have

$$
d\left(T x^{*}, T y^{*}, a\right) \leq \frac{1}{2}\left[d\left(x^{*}, T y^{*}, a\right)+d\left(y^{*}, T x^{*}, a\right)\right]-\psi\left(d\left(x^{*}, T y^{*}, a\right), d\left(y^{*}, T x^{*}, a\right)\right)
$$

for all $a \in X$. This implies

$$
d\left(x^{*}, y^{*}, a\right) \leq d\left(x^{*}, y^{*}, a\right)-\psi\left(d\left(x^{*}, y^{*}, a\right), d\left(x^{*}, y^{*}, a\right)\right) \leq d\left(x^{*}, y^{*}, a\right) .
$$

That is, $\psi\left(d\left(x^{*}, y^{*}, a\right), d\left(x^{*}, y^{*}, a\right)\right)=0$ for all $a \in X$. So, $d\left(x^{*}, y^{*}, a\right)=0$ for all $a \in X$. Hence, $x^{*}=y^{*}$.

Case 2: Let $\alpha\left(x^{*}, y^{*}, a\right)<\eta\left(x^{*}, y^{*}, a\right)$ and $\alpha\left(y^{*}, x^{*}, a\right)<\eta\left(y^{*}, x^{*}, a\right)$ for all $a \in X$. From (A) there exists $z \in X$ such that

$$
\alpha\left(x^{*}, z, a\right) \geq \eta\left(x^{*}, z, a\right) \quad \text { or } \quad \alpha\left(z, x^{*}, a\right) \geq \eta\left(z, x^{*}, a\right)
$$


and

$$
\alpha\left(y^{*}, z, a\right) \geq \eta\left(y^{*}, z, a\right) \quad \text { or } \quad \alpha\left(z, y^{*}, a\right) \geq \eta\left(z, y^{*}, a\right) .
$$

Without loss of generality we can assume

$$
\alpha\left(x^{*}, z, a\right) \geq \eta\left(x^{*}, z, a\right) \quad \text { and } \quad \alpha\left(y^{*}, z, a\right) \geq \eta\left(y^{*}, z, a\right) .
$$

Now, since $T$ is a triangular $2-\alpha-\eta$-admissible mapping, then

$$
\begin{aligned}
& \alpha\left(T x^{*}, T\left(T^{n-1} z\right), a\right) \geq \eta\left(T x^{*}, T\left(T^{n-1} z\right), a\right), \\
& \alpha\left(T y^{*}, T\left(T^{n-1} z\right), a\right) \geq \eta\left(T y^{*}, T\left(T^{n-1} z\right), a\right)
\end{aligned}
$$

for all $n \in \mathbb{N} \cup 0$ and all $a \in X$. Then from (2.2) we get

$$
\begin{aligned}
d\left(T x^{*}, T\left(T^{n-1} z\right), a\right) \leq & \frac{1}{2}\left[d\left(x^{*}, T\left(T^{n-1} z\right), a\right)+d\left(T^{n-1} z, T x^{*}, a\right)\right] \\
& -\psi\left(d\left(x^{*}, T\left(T^{n-1} z\right), a\right), d\left(T^{n-1} z, T x^{*}, a\right)\right)
\end{aligned}
$$

which implies

$$
\begin{aligned}
d\left(x^{*}, T^{n} z, a\right) & \leq \frac{1}{2}\left[d\left(x^{*}, T^{n} z, a\right)+d\left(x^{*}, T^{n-1} z, a\right)\right]-\psi\left(d\left(x^{*}, T^{n} z, a\right), d\left(x^{*}, T^{n-1} z, a\right)\right) \\
& \leq \frac{1}{2}\left[d\left(x^{*}, T^{n} z, a\right)+d\left(x^{*}, T^{n-1} z, a\right)\right]
\end{aligned}
$$

which implies $d\left(x^{*}, T^{n} z, a\right) \leq d\left(x^{*}, T^{n-1} z, a\right)$. Then there exists $\ell \in \mathbb{R}$ such that $\lim _{n \rightarrow \infty} d\left(x^{*}, T^{n} z, a\right)=\ell$. By taking limit as $n \rightarrow \infty$ in (2.20), we get

$$
\ell \leq \frac{1}{2}(\ell+\ell)-\psi(\ell, \ell) \leq \ell
$$

and so $\psi(\ell, \ell)=0$. Therefore, $\ell=0$. That is, $\lim _{n \rightarrow \infty} T^{n} z=x^{*}$. Similarly, we can deduce $\lim _{n \rightarrow \infty} T^{n} z=y^{*}$. Then by Lemma 1.1 we get $x^{*}=y^{*}$.

\section{Fixed point results for rational contraction in 2-metric spaces}

In this section, we prove certain fixed point theorems for a rational contraction mapping via a triangular $2-\alpha-\eta$-admissible mapping.

Denote with $\Psi_{\varphi}$ the family of continuous functions $\varphi:[0, \infty) \rightarrow[0, \infty)$ such that $\varphi(t)=$ 0 if and only if $t=0$.

Definition 3.1 Let $(X, d)$ be a 2-metric space and $T: X \rightarrow X, \alpha, \eta: X \times X \times X \rightarrow[0,+\infty)$ be three mappings.

- We say that $T$ is a modified rational $\alpha-\eta-\varphi$-contraction mapping if

$$
\begin{aligned}
x, y & \in X, \quad \alpha(x, y, a) \geq \eta(x, y, a) \\
\Longrightarrow & d(T x, T y, a) \leq M(x, y, a)-\varphi(M(x, y, a))
\end{aligned}
$$


for all $a \in X$, where $\varphi \in \Psi_{\varphi}$ and

$$
\begin{aligned}
M(x, y, a)= & \max \left\{d(x, y, a), d(x, T x, a), d(y, T y, a), \frac{d(x, T y, a)+d(y, T x, a)}{2},\right. \\
& \left.\frac{d(x, T x, a) d(y, T y, a)}{1+d(T x, T y, a)}\right\} .
\end{aligned}
$$

- We say that $T$ is a modified rational $\alpha-\varphi$-contraction mapping if

$$
x, y \in X, \quad \alpha(x, y, a) \geq 1 \quad \Longrightarrow \quad d(T x, T y, a) \leq M(x, y, a)-\varphi(M(x, y, a))
$$

for all $a \in X$, where $\varphi \in \Psi_{\varphi}$.

- We say that $T$ is a modified rational $\eta$ - $\varphi$-contraction mapping if

$$
x, y \in X, \quad \eta(x, y, a) \leq 1 \quad \Longrightarrow \quad d(T x, T y, a) \leq M(x, y, a)-\varphi(M(x, y, a))
$$

for all $a \in X$, where $\varphi \in \Psi_{\varphi}$.

- We say that $T$ is a rational $\alpha-\varphi$-contraction mapping if

$$
\alpha(x, y, a) d(T x, T y, a) \leq M(x, y, a)-\varphi(M(x, y, a))
$$

for all $x, y, a \in X$, where $\varphi \in \Psi_{\varphi}$.

- We say that $T$ is a rational $\eta$ - $\varphi$-contraction mapping if

$$
d(T x, T y, a) \leq \eta(x, y, a) M(x, y, a)-\varphi(M(x, y, a))
$$

for all $x, y, a \in X$, where $\varphi \in \Psi_{\varphi}$.

Theorem 3.1 Let $(X, d)$ be a complete 2 -metric space. Assume that $T: X \rightarrow X$ is a modified rational $\alpha-\eta-\varphi$-contraction mapping satisfying the following assertions:

(i) $T$ is a triangular 2- $\alpha-\eta$-admissible mapping;

(ii) there exists $x_{0}$ in $X$ such that $\alpha\left(x_{0}, T x_{0}, a\right) \geq \eta\left(x_{0}, T x_{0}, a\right)$ for all $a \in X$;

(iii) $T$ is continuous or 2- $\alpha-\eta$-continuous; or

(iv) if $\left\{x_{n}\right\}$ is a sequence in $X$ such that $\alpha\left(x_{n}, x_{n+1}, a\right) \geq \eta\left(x_{n}, x_{n+1}, a\right)$ for all $a \in X$ and $x_{n} \rightarrow x$ as $n \rightarrow \infty$, then $\alpha\left(x_{n}, x, a\right) \geq \eta\left(x_{n}, x, a\right)$ for all $n \in \mathbb{N}$ and all $a \in X$.

Then $T$ has a fixed point.

Proof Let $x_{0} \in X$ such that $\alpha\left(x_{0}, T x_{0}, a\right) \geq \eta\left(x_{0}, T x_{0}, a\right)$ for all $a \in X$. Define a sequence $\left\{x_{n}\right\}$ by $x_{n}=T^{n} x_{0}$ for all $n \in \mathbb{N}$. Now, since $T$ is a triangular $2-\alpha-\eta$-admissible mapping, so by Lemma 2.1 we have

$$
\alpha\left(x_{m}, x_{n}, a\right) \geq \eta\left(x_{m}, x_{n}, a\right) \quad \text { for all } m, n \in \mathbb{N} \text { with } m<n \text { and for all } a \in X \text {. }
$$

From (3.1) we deduce

$$
d\left(x_{n+1}, x_{n}, a\right)=d\left(T x_{n}, T x_{n-1}, a\right) \leq M\left(x_{n}, x_{n-1}, a\right)-\varphi\left(M\left(x_{n}, x_{n-1}, a\right)\right),
$$


where

$$
\begin{aligned}
M\left(x_{n}, x_{n-1}, a\right)= & \max \left\{d\left(x_{n}, x_{n-1}, a\right), d\left(x_{n}, T x_{n}, a\right), d\left(x_{n-1}, T x_{n-1}, a\right),\right. \\
& \left.\frac{d\left(x_{n}, T x_{n-1}, a\right), d\left(x_{n-1}, T x_{n}, a\right)}{2}, \frac{d\left(x_{n}, T x_{n}, a\right) d\left(x_{n-1}, T x_{n-1}, a\right)}{1+d\left(T x_{n}, T x_{n-1}, a\right)}\right\} \\
= & \max \left\{d\left(x_{n}, x_{n-1}, a\right), d\left(x_{n}, x_{n+1}, a\right), d\left(x_{n-1}, x_{n}, a\right),\right. \\
& \left.\frac{d\left(x_{n}, x_{n}, a\right)+d\left(x_{n-1}, x_{n+1}, a\right)}{2}, \frac{d\left(x_{n}, x_{n+1}, a\right) d\left(x_{n-1}, x_{n}, a\right)}{1+d\left(x_{n+1}, x_{n}, a\right)}\right\} \\
= & \max \left\{d\left(x_{n}, x_{n-1}, a\right), d\left(x_{n}, x_{n+1}, a\right), \frac{d\left(x_{n-1}, x_{n+1}, a\right)}{2},\right. \\
& \left.\frac{d\left(x_{n}, x_{n+1}, a\right) d\left(x_{n-1}, x_{n}, a\right)}{1+d\left(x_{n+1}, x_{n}, a\right)}\right\} \\
\leq & \max \left\{d\left(x_{n}, x_{n-1}, a\right), d\left(x_{n}, x_{n+1}, a\right), \frac{d\left(x_{n-1}, x_{n+1}, a\right)}{2},\right. \\
& \left.\frac{\left(1+d\left(x_{n}, x_{n+1}, a\right)\right) d\left(x_{n-1}, x_{n}, a\right)}{1+d\left(x_{n+1}, x_{n}, a\right)}\right\} \\
= & \max \left\{d\left(x_{n}, x_{n-1}, a\right), d\left(x_{n}, x_{n+1}, a\right), \frac{d\left(x_{n-1}, x_{n+1}, a\right)}{2}\right\},
\end{aligned}
$$

and so

$$
M\left(x_{n}, x_{n-1}, a\right)=\max \left\{d\left(x_{n}, x_{n-1}, a\right), d\left(x_{n}, x_{n+1}, a\right), \frac{d\left(x_{n-1}, x_{n+1}, a\right)}{2}\right\} .
$$

By taking $a=x_{n-1}$ in (3.3), we have

$$
d\left(x_{n+1}, x_{n}, x_{n-1}\right) \leq d\left(x_{n}, x_{n+1}, x_{n-1}\right)-\varphi\left(d\left(x_{n}, x_{n+1}, x_{n-1}\right)\right),
$$

and then $\varphi\left(d\left(x_{n}, x_{n+1}, x_{n-1}\right)\right)=0$, i.e., $d\left(x_{n}, x_{n+1}, x_{n-1}\right)=0$. Hence,

$$
\begin{aligned}
\max & \left\{d\left(x_{n}, x_{n-1}, a\right), d\left(x_{n}, x_{n+1}, a\right)\right\} \\
\leq & M\left(x_{n}, x_{n-1}, a\right) \\
= & \max \left\{d\left(x_{n}, x_{n-1}, a\right), d\left(x_{n}, x_{n+1}, a\right), \frac{d\left(x_{n-1}, x_{n+1}, a\right)}{2}\right\} \\
\leq & \max \left\{d\left(x_{n}, x_{n-1}, a\right), d\left(x_{n}, x_{n+1}, a\right),\right. \\
& \left.\frac{1}{2}\left[d\left(x_{n-1}, x_{n}, a\right)+d\left(x_{n}, x_{n+1}, a\right)+d\left(x_{n-1}, x_{n}, x_{n+1}\right)\right]\right\} \\
= & \max \left\{d\left(x_{n}, x_{n-1}, a\right), d\left(x_{n}, x_{n+1}, a\right), \frac{1}{2}\left[d\left(x_{n-1}, x_{n}, a\right)+d\left(x_{n}, x_{n+1}, a\right)\right]\right\} \\
= & \max \left\{d\left(x_{n}, x_{n-1}, a\right), d\left(x_{n}, x_{n+1}, a\right)\right\} .
\end{aligned}
$$

Therefore, $M\left(x_{n}, x_{n-1}, a\right)=\max \left\{d\left(x_{n}, x_{n-1}, a\right), d\left(x_{n}, x_{n+1}, a\right)\right\}$. 
If $M\left(x_{n}, x_{n-1}, a\right)=d\left(x_{n}, x_{n+1}, a\right)$, then from (3.3) we get

$$
d\left(x_{n+1}, x_{n}, a\right) \leq d\left(x_{n}, x_{n+1}, a\right)-\varphi\left(d\left(x_{n}, x_{n+1}, a\right)\right) .
$$

Thus, $\varphi\left(d\left(x_{n}, x_{n+1}, a\right)\right)=0$, i.e., $d\left(x_{n}, x_{n+1}, a\right)=0$ for all $a \in X$. Hence by Definition 1.1(d1), $x_{n}=x_{n+1}=T x_{n}$ for all $n \in \mathbb{N}$. Then $x=x_{n}$ is a fixed point of $T$. Now, if $M\left(x_{n}, x_{n-1}, a\right)=$ $d\left(x_{n}, x_{n-1}, a\right)$, then from (3.3) we get

$$
d\left(x_{n+1}, x_{n}, a\right) \leq d\left(x_{n}, x_{n-1}, a\right)-\varphi\left(d\left(x_{n}, x_{n-1}, a\right)\right) \leq d\left(x_{n}, x_{n-1}, a\right) .
$$

So, the sequence $\left\{d\left(x_{n+1}, x_{n}, a\right)\right\}$ is decreasing in $\mathbb{R}_{+}$and so it is convergent to $r \in \mathbb{R}_{+}$, i.e., $\lim _{n \rightarrow \infty} d\left(x_{n+1}, x_{n}, a\right)=r$. Taking limit in (3.4) we get

$$
r \leq r-\varphi(r)
$$

which implies $r=0$. Hence,

$$
\lim _{n \rightarrow \infty} d\left(x_{n+1}, x_{n}, a\right)=0 .
$$

From (2.13) in Theorem 2.1 we have $d\left(x_{i}, x_{j}, x_{k}\right)=0$ for all $i, j, k \in \mathbb{N}$. We now show that $\left\{x_{n}\right\}$ is a Cauchy sequence. Suppose to the contrary that $\left\{x_{n}\right\}$ is not a Cauchy sequence. Then there are $\varepsilon>0$ and sequences $\{m(k)\}$ and $\{n(k)\}$ such that for all positive integers $k$,

$$
n(k)>m(k)>k, \quad d\left(x_{n(k)}, x_{m(k)}, a\right) \geq \varepsilon \quad \text { and } \quad d\left(x_{n(k)-1}, x_{m(k)}, a\right)<\varepsilon .
$$

As in the proof of Theorem 2.1, we get

$$
\begin{aligned}
& \lim _{k \rightarrow \infty} d\left(x_{n(k)}, x_{m(k)}, a\right)=\lim _{k \rightarrow \infty} d\left(x_{n(k)-1}, x_{m(k)}, a\right)=\epsilon ; \\
& \lim _{k \rightarrow \infty} d\left(x_{m(k)-1}, x_{n(k)}, a\right)=\epsilon .
\end{aligned}
$$

Now since $n(k)>m(k)$, so by (3.2) we have

$$
\alpha\left(x_{m(k)-1}, x_{n(k)-1}, a\right) \geq \eta\left(x_{m(k)-1}, x_{n(k)-1}, a\right)
$$

for all $a \in X$. So by (3.1) we get

$$
\begin{aligned}
d\left(x_{m(k)}, x_{n(k)}, a\right) & =d\left(T x_{m(k)-1}, T x_{n(k)-1}, a\right) \\
& \leq M\left(x_{m(k)-1}, x_{n(k)-1}, a\right)-\varphi\left(M\left(x_{m(k)-1}, x_{n(k)-1}, a\right)\right),
\end{aligned}
$$

where

$$
\begin{aligned}
M\left(x_{m(k)-1}, x_{n(k)-1}, a\right)= & \max \left\{d\left(x_{m(k)-1}, x_{n(k)-1}, a\right), d\left(x_{m(k)-1}, T x_{m(k)-1}, a\right),\right. \\
& d\left(x_{n(k)-1}, T x_{n(k)-1}, a\right), \\
& \frac{d\left(x_{m(k)-1}, T x_{n(k)-1}, a\right)+d\left(x_{n(k)-1}, T x_{m(k)-1}, a\right)}{2},
\end{aligned}
$$




$$
\begin{aligned}
& \left.\frac{d\left(x_{m(k)-1}, T x_{m(k)-1}, a\right) d\left(x_{n(k)-1}, T x_{n(k)-1}, a\right)}{1+d\left(T x_{m(k)-1}, T x_{n(k)-1}, a\right)}\right\} \\
= & \max \left\{d\left(x_{m(k)-1}, x_{n(k)-1}, a\right), d\left(x_{m(k)-1}, x_{m(k)}, a\right),\right. \\
& d\left(x_{n(k)-1}, x_{n(k)}, a\right), \\
& \frac{d\left(x_{m(k)-1}, x_{n(k)}, a\right)+d\left(x_{n(k)-1}, x_{m(k)}, a\right)}{2}, \\
& \left.\frac{d\left(x_{m(k)-1}, x_{m(k)}, a\right) d\left(x_{n(k)-1}, x_{n(k)}, a\right)}{1+d\left(x_{m(k)}, x_{n(k)}, a\right)}\right\} .
\end{aligned}
$$

Taking limit as $k \rightarrow \infty$ in (3.9) and applying (3.7) and (3.8), we deduce

$$
\epsilon \leq \lim _{k \rightarrow \infty} M\left(x_{m(k)-1}, x_{n(k)-1}, a\right)-\lim _{k \rightarrow \infty} \varphi\left(M\left(x_{m(k)-1}, x_{n(k)-1}, a\right)\right),
$$

where $\lim _{k \rightarrow \infty} M\left(x_{m(k)-1}, x_{n(k)-1}, a\right)=\epsilon$. Then $\varphi(\epsilon)=0$, i.e., $\epsilon=0$, which is a contradiction. Hence, $\left\{x_{n}\right\}$ is a Cauchy sequence. Now, since $(X, d)$ is a complete 2-metric space, then there exists $x^{*} \in X$ such that $\lim _{n \rightarrow \infty} x_{n}=x^{*}$. At first we assume that (iii) holds. That is, $T$ is continuous or $2-\alpha-\eta$-continuous. Then

$$
x^{*}=\lim _{n \rightarrow \infty} x_{n+1}=\lim _{n \rightarrow \infty} T x_{n}=T x^{*} .
$$

That is, $x^{*}$ is a fixed point of $T$. Next we assume that (iv) holds. That is, $\alpha\left(x_{n}, x^{*}, a\right) \geq$ $\eta\left(x_{n}, x^{*}, a\right)$ for all $n \in \mathbb{N}$ and all $a \in X$. Then by (3.1) we get

$$
d\left(x_{n+1}, T x^{*}, a\right)=d\left(T x_{n}, T x^{*}, a\right) \leq M\left(x_{n}, x^{*}, a\right)-\varphi\left(M\left(x_{n}, x^{*}, a\right)\right)
$$

for all $a \in X$, where $\varphi \in \Psi_{\varphi}$ and

$$
\begin{aligned}
M\left(x_{n}, x^{*}, a\right)= & \max \left\{d\left(x_{n}, x^{*}, a\right), d\left(x_{n}, T x_{n}, a\right), d\left(x^{*}, T x^{*}, a\right),\right. \\
& \left.\frac{d\left(x_{n}, T x^{*}, a\right)+d\left(x^{*}, T x_{n}, a\right)}{2}, \frac{d\left(x_{n}, T x_{n}, a\right) d\left(x^{*}, T x^{*}, a\right)}{1+d\left(T x_{n}, T x^{*}, a\right)}\right\} \\
= & \max \left\{d\left(x_{n}, x^{*}, a\right), d\left(x_{n}, x_{n+1}, a\right), d\left(x^{*}, T x^{*}, a\right),\right. \\
& \left.\frac{d\left(x_{n}, T x^{*}, a\right)+d\left(x^{*}, x_{n+1}, a\right)}{2}, \frac{d\left(x_{n}, x_{n+1}, a\right) d\left(x^{*}, T x^{*}, a\right)}{1+d\left(x_{n+1}, T x^{*}, a\right)}\right\} .
\end{aligned}
$$

Taking limit as $n \rightarrow \infty$ in the above inequality, we deduce

$$
d\left(x^{*}, T x^{*}, a\right) \leq \lim _{n \rightarrow \infty} M\left(x_{n}, x^{*}, a\right)-\lim _{n \rightarrow \infty} \varphi\left(M\left(x_{n}, x^{*}, a\right)\right) .
$$

Since $\lim _{n \rightarrow \infty} M\left(x_{n}, x^{*}, a\right)=d\left(x^{*}, T x^{*}, a\right)$, then $\varphi\left(d\left(x^{*}, T x^{*}, a\right)\right)=0$, i.e., $d\left(x^{*}, T x^{*}, a\right)=0$ for all $a \in X$. Thus, $x^{*}=T x^{*}$.

Corollary 3.1 Let $(X, d)$ be a complete 2-metric space. Assume that $T: X \rightarrow X$ is a modified rational $\alpha-\varphi$-contraction mapping satisfying the following assertions: 
(i) $T$ is a triangular 2- $\alpha$-admissible mapping;

(ii) there exists $x_{0}$ in $X$ such that $\alpha\left(x_{0}, T x_{0}, a\right) \geq 1$ for all $a \in X$;

(iii) $T$ is continuous or 2- $\alpha$-continuous; or

(iv) if $\left\{x_{n}\right\}$ is a sequence in $X$ such that $\alpha\left(x_{n}, x_{n+1}, a\right) \geq 1$ for all $a \in X$ and $x_{n} \rightarrow x$ as $n \rightarrow \infty$, then $\alpha\left(x_{n}, x, a\right) \geq 1$ for all $n \in \mathbb{N}$ and all $a \in X$.

Then $T$ has a fixed point.

Example 3.1 Let $X=[0, \infty)$. We define a 2-metric $d$ on $X$ by

$$
d(x, y, a)=\min \{\sigma(x, y), \sigma(y, a), \sigma(x, a)\}
$$

where

$$
\sigma(u, v)= \begin{cases}\max \{u, v\} & \text { if } u \neq v \\ 0 & \text { if } u=v\end{cases}
$$

Clearly, $(X, d)$ is a complete 2 -metric space. Define $T: X \rightarrow X, \varphi:[0, \infty) \rightarrow[0, \infty)$ and $\alpha: X \times X \times X \rightarrow[0, \infty)$ by

$$
T x=\left\{\begin{array}{ll}
\frac{1}{4} & \text { if } x \in[0,1], \\
\cos x+2 & \text { if } x \in(1,300], \\
x^{3}+x+1 & \text { if } x \in[300, \infty)
\end{array} \quad \psi(t)=\frac{t}{2}\right.
$$

and

$$
\alpha(x, y, a)= \begin{cases}1 & \text { if } x, y \in[0,1] \text { and } a=0 \\ \frac{1}{2} & \text { otherwise }\end{cases}
$$

Now, we prove that all the hypotheses of Corollary 3.1 (Theorem 3.1) are satisfied and hence $T$ has a fixed point.

Proof As in the proof of Example 2.3 we can show that $T$ is a 2- $\alpha$-admissible mapping, $\alpha(0, T 0, a) \geq 1$ for all $a \in X$ and if $\left\{x_{n}\right\}$ is a sequence in $X$ such that $\alpha\left(x_{n}, x_{n+1}, a\right) \geq 1$ for all $n \in \mathbb{N} \cup\{0\}$ and $a \in X$ and $x_{n} \rightarrow x$ as $n \rightarrow+\infty$, then $\alpha\left(x_{n}, x, a\right) \geq 1$ for all $n \in \mathbb{N} \cup\{0\}$ and all $a \in X$.

Let $\alpha(x, y, a) \geq 1$. Then $x, y \in[0,1]$ and hence

$$
d(T x, T y, a)=0 \leq M(x, y, a)-\varphi(M(x, y, a)) .
$$

That is,

$$
\alpha(x, y, a) \geq 1 \quad \Longrightarrow \quad d(T x, T y, a) \leq M(x, y, a)-\varphi(M(x, y, a))
$$

for all $a \in X$. Hence, $T$ is a modified rational $\alpha-\varphi$-contraction mapping. Then all the conditions of Corollary 3.1 (Theorem 3.1) are satisfied and hence $T$ has a fixed point.

By taking $\alpha(x, y, a)=1$ in Theorem 3.1, we have the following corollary. 
Corollary 3.2 Let $(X, d)$ be a complete 2 -metric space. Assume that $T: X \rightarrow X$ is a modified rational $\eta-\varphi$-contraction mapping satisfying the following assertions:

(i) $T$ is a triangular 2- $\eta$-admissible mapping;

(ii) there exists $x_{0}$ in $X$ such that $\eta\left(x_{0}, T x_{0}, a\right) \leq 1$ for all $a \in X$;

(iii) $T$ is continuous or 2- $\eta$-continuous; or

(iv) if $\left\{x_{n}\right\}$ is a sequence in $X$ such that $\eta\left(x_{n}, x_{n+1}, a\right) \leq 1$ for all $a \in X$ and $x_{n} \rightarrow x$ as $n \rightarrow \infty$, then $\eta\left(x_{n}, x, a\right) \leq 1$ for all $n \in \mathbb{N}$ and all $a \in X$.

Then $T$ has a fixed point.

Corollary 3.3 Let $(X, d)$ be a complete 2 -metric space. Assume that $T: X \rightarrow X$ is a rational $\alpha-\varphi$-contraction mapping satisfying the following assertions:

(i) $T$ is a triangular 2- $\alpha$-admissible mapping;

(ii) there exists $x_{0}$ in $X$ such that $\alpha\left(x_{0}, T x_{0}, a\right) \geq 1$ for all $a \in X$;

(iii) $T$ is continuous or 2- $\alpha$-continuous; or

(iv) if $\left\{x_{n}\right\}$ is a sequence in $X$ such that $\alpha\left(x_{n}, x_{n+1}, a\right) \geq 1$ for all $a \in X$ and $x_{n} \rightarrow x$ as $n \rightarrow \infty$, then $\alpha\left(x_{n}, x, a\right) \geq 1$ for all $n \in \mathbb{N}$ and all $a \in X$.

Then $T$ has a fixed point.

Corollary 3.4 Let $(X, d)$ be a complete 2-metric space. Assume that $T: X \rightarrow X$ is a rational $\eta$ - $\varphi$-contraction mapping satisfying the following assertions:

(i) $T$ is a triangular 2- $\eta$-admissible mapping;

(ii) there exists $x_{0}$ in $X$ such that $\eta\left(x_{0}, T x_{0}, a\right) \leq 1$ for all $a \in X$;

(iii) $T$ is continuous or 2- $\eta$-continuous; or

(iv) if $\left\{x_{n}\right\}$ is a sequence in $X$ such that $\eta\left(x_{n}, x_{n+1}, a\right) \leq 1$ for all $a \in X$ and $x_{n} \rightarrow x$ as $n \rightarrow \infty$, then $\eta\left(x_{n}, x, a\right) \leq 1$ for all $n \in \mathbb{N}$ and all $a \in X$.

Then $T$ has a fixed point.

\section{Fixed point results in partially ordered 2-metric spaces}

Recently, there have been so many exciting developments in the field of existence of fixed points in partially ordered sets. This approach was initiated by Ran and Reurings [28] and they also provided some applications to matrix equations. Their results are a hybrid of the two classical theorems: Banach's fixed point theorem and Tarski's fixed point theorem. Agarwal et al. [29], Bhaskar and Lakshmikantham [30], Ciric et al. [31] and Hussain et al. $[32,33]$ presented some new results for nonlinear contractions in partially ordered metric spaces and noted that their theorems can be used to investigate a large class of problems. In this section, as an application of obtained results we prove some fixed point results in partially ordered 2-metric spaces. We also note that the recent fixed point results in [34] can be deduced as simple corollaries.

Recall that if $(X, \preceq)$ is a partially ordered set and $T: X \rightarrow X$ is such that for $x, y \in X, x \preceq y$ implies $T x \preceq T y$, then the mapping $T$ is said to be non-decreasing.

Theorem 4.1 (Theorems 2.3 and 2.4 of [34]) Let $(X, d, \preceq)$ be a complete partially ordered 2-metric space. Assume that $T: X \rightarrow X$ is a mapping satisfying the following assertions:

(i) $T$ is non-decreasing;

(ii) there exists $x_{0}$ in $X$ such that $x_{0} \preceq T x_{0}$;

(iii) $T$ is continuous; or 
(iv) if $\left\{x_{n}\right\}$ is a non-decreasing sequence in $X$ such that $x_{n} \rightarrow x$ as $n \rightarrow \infty$, then $x_{n} \preceq x$ for all $n \in \mathbb{N}$;

(v)

$$
d(T x, T y, a) \leq \frac{1}{2}[d(x, T y, a)+d(y, T x, a)]-\psi(d(x, T y, a), d(y, T x, a))
$$

holds for all $x, y, a \in X$ with $x \preceq y$ or $y \preceq x$, where $\psi \in \Psi$.

Then $T$ has a fixed point.

Proof Define the mapping $\alpha: X \times X \times X \rightarrow \mathbb{R}_{+}$by

$$
\alpha(x, y, a)= \begin{cases}1 & \text { if } x \preceq y \\ 0 & \text { otherwise }\end{cases}
$$

Let $\alpha(x, y, a) \geq 1$, then $x \preceq y$. From (4.1) we get

$$
d(T x, T y, a) \leq \frac{1}{2}[d(x, T y, a)+d(y, T x, a)]-\psi(d(x, T y, a), d(y, T x, a)) .
$$

Again let $x, y, a \in X$ such that $\alpha(x, y, a) \geq 1$. This implies that $x \preceq y$. As the mapping $T$ is non-decreasing, we deduce that $T x \preceq T y$ and hence $\alpha(T x, T y, a) \geq 1$ for all $a \in X$. Also, let $\alpha(x, z, a) \geq 1$ and $\alpha(z, y, a) \geq 1$, then $x \preceq z$ and $z \preceq y$. So from transitivity we have $x \preceq y$. That is, $\alpha(x, y, a) \geq 1$ for all $a \in X$. Thus $T$ is a triangular 2 - $\alpha$-admissible mapping. The condition (ii) ensures that there exists $x_{0} \in X$ such that $x_{0} \preceq T x_{0}$. This implies that $\alpha\left(x_{0}, T x_{0}, a\right) \geq 1$ for all $a \in X$. Let $\left\{x_{n}\right\}$ be a sequence in $X$ such that $\alpha\left(x_{n}, x_{n+1}, a\right) \geq 1$ for all $a \in X$ and all $n \in \mathbb{N}$ and $x_{n} \rightarrow x$ as $n \rightarrow \infty$. So, $x_{n} \preceq x_{n+1}$ for all $n \in \mathbb{N}$. Then from (iv) we have $x_{n} \preceq x$ for all $n \in \mathbb{N}$. That is, $\alpha\left(x_{n}, x, a\right) \geq 1$ for all $n \in \mathbb{N}$ and all $a \in X$. Therefore, all the conditions of Corollary 2.1 are satisfied, so $T$ has a fixed point in $X$.

(B) For all $x, y \in X$ which are not comparable, there exists $z \in X$ that is comparable to $x$ and $y$.

Theorem 4.2 (Theorem 2.5 of [34]) Adding condition (B) to the hypotheses of Theorem 4.1, we obtain the uniqueness of the fixed point of $T$.

Proof Define the mapping $\alpha: X \times X \times X \rightarrow \mathbb{R}_{+}$as in the proof of Theorem 4.1. Let $x, y \in X$, where $\alpha(x, y, a)<1$ and $\alpha(y, x, a)<1$ for all $a \in X$. That is, $x$ and $y$ are not comparable. Hence, by condition (B) there exists $z \in X$ that is comparable to $x$ and $y$, i.e., $z \preceq x$ or $x \preceq z$ and $z \preceq y$ or $y \preceq x$. That is, $\alpha(z, x, a) \geq 1$ or $\alpha(x, z, a) \geq 1$ and $\alpha(z, y, a) \geq 1$ or $\alpha(y, z, a) \geq 1$ for all $a \in X$. Then the conditions of Theorem 2.2 hold and the fixed point of $T$ is unique.

Theorem 4.3 Let $(X, d, \preceq)$ be a complete partially ordered 2-metric space. Assume that $T: X \rightarrow X$ is a mapping satisfying the following assertions:

(i) $T$ is non-decreasing;

(ii) there exists $x_{0}$ in $X$ such that $x_{0} \preceq T x_{0}$;

(iii) $T$ is continuous; or 
(iv) if $\left\{x_{n}\right\}$ is a non-decreasing sequence in $X$ such that $x_{n} \rightarrow x$ as $n \rightarrow \infty$, then $x_{n} \preceq x$ for all $n \in \mathbb{N}$;

(v) $T$ is an ordered modified rational $\varphi$-contraction mapping, that is,

$$
d(T x, T y, a) \leq M(x, y, a)-\varphi(M(x, y, a))
$$

holds for all $x, y, a \in X$ with $x \preceq y$ or $y \preceq x$, where $\varphi \in \Psi_{\varphi}$ and

$$
\begin{aligned}
M(x, y, a)= & \max \left\{d(x, y, a), d(x, T x, a), d(y, T y, a), \frac{d(x, T y, a)+d(y, T x, a)}{2},\right. \\
& \left.\frac{d(x, T x, a) d(y, T y, a)}{1+d(T x, T y, a)}\right\} .
\end{aligned}
$$

Then T has a fixed point.

Proof Define the mapping $\alpha: X \times X \times X \rightarrow \mathbb{R}_{+}$by

$$
\alpha(x, y, a)= \begin{cases}1 & \text { if } x \preceq y \\ 0 & \text { otherwise }\end{cases}
$$

Let $\alpha(x, y, a) \geq 1$, then $x \preceq y$. From (4.2) we get

$$
d(T x, T y, a) \leq M(x, y, a)-\varphi(M(x, y, a)) .
$$

Again let $x, y, a \in X$ such that $\alpha(x, y, a) \geq 1$. This implies that $x \preceq y$. As the mapping $T$ is non-decreasing, we deduce that $T x \preceq T y$ and hence $\alpha(T x, T y, a) \geq 1$ for all $a \in X$. Also, let $\alpha(x, z, a) \geq 1$ and $\alpha(z, y, a) \geq 1$, then $x \preceq z$ and $z \preceq y$. So from transitivity we have $x \preceq y$. That is, $\alpha(x, y, a) \geq 1$ for all $a \in X$. Thus $T$ is a triangular 2 - $\alpha$-admissible mapping. The condition (ii) ensures that there exists $x_{0} \in X$ such that $x_{0} \preceq T x_{0}$. This implies that $\alpha\left(x_{0}, T x_{0}, a\right) \geq 1$ for all $a \in X$. Let $\left\{x_{n}\right\}$ be a sequence in $X$ such that $\alpha\left(x_{n}, x_{n+1}, a\right) \geq 1$ for all $a \in X$ and all $n \in \mathbb{N}$ and $x_{n} \rightarrow x$ as $n \rightarrow \infty$. So, $x_{n} \preceq x_{n+1}$ for all $n \in \mathbb{N}$. Then from (iv) we have $x_{n} \preceq x$ for all $n \in \mathbb{N}$. That is, $\alpha\left(x_{n}, x, a\right) \geq 1$ for all $n \in \mathbb{N}$ and all $a \in X$. Therefore, all the conditions of Corollary 3.1 are satisfied, so $T$ has a fixed point in $X$.

\section{Application to existence of solutions of integral equations}

Integral equations like (5.1) have been studied in many papers (see, e.g., [32, 35, 36] and the references therein). In this section, we look for a solution to (5.1) in $X=C([0, T], \mathbb{R})$. For the remainder, we gather some definitions from the literature which will be used in the sequel. Let $X=C([0, T], \mathbb{R})$ be the set of real continuous functions defined on $[0, T]$, and let $d: X \times X \times X \rightarrow \mathbb{R}_{+}$be defined by

$$
d(x(t), y(t), a(t))=\|\min \{|x(t)-y(t)|,|y(t)-a(t)|,|x(t)-a(t)|\}\|_{\infty}
$$

for all $x, y, a \in X$. Then $(X, d)$ is a complete 2-metric space.

Consider the integral equation

$$
x(t)=p(t)+\int_{0}^{T} S(t, s) f(s, x(s)) d s,
$$


and let $F: X \rightarrow X$ be defined by

$$
F(x)(t)=p(t)+\int_{0}^{T} S(t, s) f(s, x(s)) d s
$$

We assume that

(A) $f:[0, T] \times \mathbb{R} \rightarrow \mathbb{R}$ is continuous;

(B) $p:[0, T] \rightarrow \mathbb{R}$ is continuous;

(C) $S:[0, T] \times \mathbb{R} \rightarrow[0,+\infty)$ is continuous and $\int_{0}^{T} S(t, s) d s \leq 1$;

(D) there exist $0 \leq r<1$ and two functions $\alpha, \eta: X \times X \times X \rightarrow[0, \infty)$ such that for all $s \in[0, T]$,

$$
\begin{gathered}
x, y \in X, \quad \alpha(x(s), y(s), a(s)) \geq \eta(x(s), y(s), a(s)) \\
\Longrightarrow \quad \alpha(F x(s), F y(s), a(s)) \geq \eta(F x(s), F y(s), a(s))
\end{gathered}
$$

for all $a \in X$ and

$$
\begin{aligned}
\eta(x(s), y(s), a(s)) & \leq \alpha(x(s), y(s), a(s)) \\
\Longrightarrow \quad|f(s, x(s))-f(s, y(s))| & \\
\leq & \frac{r}{2}[\min \{|x(s)-F y(s)|,|a(s)-F(y(s))|,|x(s)-a(s)|\} \\
& \quad+\min \{|y(s)-F x(s)|,|a(s)-F(x(s))|,|y(s)-a(s)|\}]
\end{aligned}
$$

for all $a \in X$;

(F) there exists $x_{0} \in X$ such that $\alpha\left(x_{0}, F\left(x_{0}\right), a\right) \geq \eta\left(x_{0}, F\left(x_{0}\right), a\right)$;

(G) if $\left\{x_{n}\right\}$ is a sequence in $X$ such that $\alpha\left(x_{n}, x_{n+1}, a\right) \geq \eta\left(x_{n}, x_{n+1}, a\right)$ with $x_{n} \rightarrow x$ as $n \rightarrow \infty$, then $\alpha\left(x_{n}, x, a\right) \geq \eta\left(x_{n}, x, a\right)$ for all $n \in \mathbb{N} \cup\{0\}$.

Theorem 5.1 Under the assumptions (A)-(G), the integral equation (5.1) has a solution in $X=C([0, T], \mathbb{R})$.

Proof Consider the mapping $F: X \rightarrow X$ defined by (5.2). Let $x, y, a \in X$ with $\eta(x, x, a) \leq$ $\alpha(x, y, a)$. From (D), we deduce that

$$
\begin{aligned}
\min & \{|F x(t)-F y(t)|,|F y(t)-a(t)|,|F x(t)-a(t)|\} \\
\leq & |F x(t)-F y(t)| \\
= & \left|\int_{0}^{T} S(t, s)[f(s, x(s))-f(s, y(s))] d s\right| \\
\leq & \int_{0}^{T} S(t, s)|f(s, x(s))-f(s, y(s))| d s \\
\leq & \int_{0}^{T} S(t, s) \frac{r}{2}[\min \{|x(s)-F y(s)|,|a(s)-F(y(s))|,|x(s)-a(s)|\} \\
& +\min \{|y(s)-F x(s)|,|a(s)-F(x(s))|,|y(s)-a(s)|\}] d s \\
\leq & \int_{0}^{T} S(t, s) \frac{r}{2}\left[\|\min \{|x(t)-F y(t)|,|a(t)-F(y(t))|,|x(t)-a(t)|\}\|_{\infty}\right.
\end{aligned}
$$




$$
\begin{aligned}
& \left.+\|\min \{|y(t)-F x(t)|,|a(t)-F(x(t))|,|y(t)-a(t)|\}\|_{\infty}\right] d s \\
\leq & \frac{r}{2}\left[\|\min \{|x(t)-F y(t)|,|a(t)-F(y(t))|,|x(t)-a(t)|\}\|_{\infty}\right. \\
& \left.+\|\min \{|y(t)-F x(t)|,|a(t)-F(x(t))|,|y(t)-a(t)|\}\|_{\infty}\right]\left(\int_{0}^{T} S(t, s) d s\right) \\
\leq & \frac{r}{2}\left[\|\min \{|x(t)-F y(t)|,|a(t)-F(y(t))|,|x(t)-a(t)|\}\|_{\infty}\right. \\
& \left.+\|\min \{|y(t)-F x(t)|,|a(t)-F(x(t))|,|y(t)-a(t)|\}\|_{\infty}\right] \\
= & \frac{r}{2}[d(x, F y, a)+d(y, F x, a)] .
\end{aligned}
$$

Therefore,

$$
d(F x, F y, a) \leq \frac{r}{2}[d(x, F y, a)+d(y, F x, a)] .
$$

That is, $\eta(x(s), y(s), a) \leq \alpha(x(s), y(s), a)$ implies

$$
d(F x, F y, a) \leq \frac{r}{2}[d(x, F y, a)+d(y, F x, a)] .
$$

Thus $F$ is a weak $\alpha-\eta$-C-contraction mapping with $\psi(s, t)=\frac{1-r}{2}[s+t]$.

Hence all the hypotheses of Theorem 2.1 are satisfied and the mapping $F$ has a fixed point which is a solution in $X=C([0, T], \mathbb{R})$ of the integral equation (5.1).

\section{Competing interests}

The authors declare that they have no competing interests.

\section{Authors' contributions}

All authors contributed equally and significantly in writing this article. All authors read and approved the final manuscript.

\section{Author details}

${ }^{1}$ Department of Mathematics, Boukan Branch, Islamic Azad University, Boukan, Iran. ${ }^{2}$ Department of Mathematics, King Abdulaziz University, P.O. Box 80203, Jeddah, 21589, Saudi Arabia.

\section{Acknowledgements}

This article was funded by the Deanship of Scientific Research (DSR), King Abdulaziz University, Jeddah. Therefore, the second and third authors acknowledge with thanks DSR, KAU for financial support. The authors would like to thank the editor and the referees for constructive comments which improved the paper considerably.

Received: 28 July 2013 Accepted: 5 December 2013 Published: 06 Jan 2014

\section{References}

1. Aliouche, A, Simpson, C: Fixed points and lines in 2-metric spaces. Adv. Math. 229, 668-690 (2012)

2. Aull, CE, Lowen, R: Handbook of the History of General Topology. Kluwer Academic, Dodrecht (2001)

3. Blumenthal, LM: Distance Geometry. Oxford University Press, London (1953)

4. Deshpande, B, Chouhan, S: Common fixed point theorems for hybrid pairs of mappings with some weaker conditions in 2-metric spaces. Fasc. Math. 46, 37-55 (2011)

5. Hadžić, O, Pap, E: Fixed Point Theory in Probabilistic Metric Spaces. Kluwer Academic, London (2001)

6. Imdad, M, Ali, J: A general fixed point theorem in fuzzy metric spaces via an implicit function. J. Appl. Math. Inform. 26(3-4), 591-603 (2008)

7. Kutbi, MA, Ahmad, J, Hussain, N, Arshad, M: Common fixed point results for mappings with rational expressions. Abstr. Appl. Anal. 2013, Article ID 549518 (2013)

8. Kirk, WA, Sims, B: Handbook of Metric Fixed Point Theory. Kluwer Academic, Dordrecht (2001)

9. Lahiri, BK, Das, P, Dey, LK: Cantor's theorem in 2-metric spaces and its applications to fixed point problems. Taiwan. J. Math. 15, 337-352 (2011)

10. Gähler, VS: 2-metrische Räume und ihre topologische struktur. Math. Nachr. 26, 115-118 (1963/64)

11. Dhage, BC: A study of some fixed point theorems. Ph.D thesis, Marathwada, Aurangabad, India (1984) 
12. Mustafa, Z, Sims, B: Some remarks concerning D-metric spaces. In: Proceedings of the International Conference on Fixed Point Theory and Applications, pp. 189-198. Valencia, Spain, July 13-19 (2004)

13. Mustafa, Z, Sims, B: A new approach to generalized metric spaces. J. Nonlinear Convex Anal. 7(2), $289-297$ (2006)

14. Hussain, N, Karapinar, E, Salimi, P, Vetro, P: Fixed point results for $G^{m}$-Meir-Keeler contractive and G- $(\alpha, \psi)$-Meir-Keeler contractive mappings. Fixed Point Theory Appl. 2013, Article ID 34 (2013)

15. Jleli, M, Samet, B: Remarks on G-metric spaces and fixed point theorems. Fixed Point Theory Appl. 2012, Article ID 201 (2012)

16. Samet, B, Vetro, C, Vetro, F: Remarks on G-metric spaces. Int. J. Anal. 2013, 1-6 (2013)

17. Du, WS: A note on cone metric fixed point theory and its equivalence. Nonlinear Anal. 72, 2259-2261 (2010)

18. Kadelburg, Z, Radenović, S, Rakočević, V: A note on the equivalence of some metric and cone metric fixed point results. Appl. Math. Lett. 24(3), 370-374 (2011)

19. Khani, M, Pourmahdian, M: On the metrizability of cone metric spaces. Topol. Appl. 158(2), 190-193 (2011)

20. Iseki, K: Fixed point theorems in 2-metric spaces. Math. Semin. Notes 3, 133-136 (1975)

21. Naidu, SVR, Prasad, JR: Fixed point theorems in 2-metric spaces. Indian J. Pure Appl. Math. 17(8), 974-993 (1986)

22. Chatterjea, SK: Fixed point theorems. C. R. Acad. Bulgare Sci. 25, 727-730 (1972)

23. Choudhury, BS: Unique fixed point theorem for weakly C-contractive mappings. J. Sci. Eng. Technol. 5, 6-13 (2009)

24. Samet, B, Vetro, C, Vetro, P: Fixed point theorem for $\alpha-\psi$ contractive type mappings. Nonlinear Anal. 75, 2154-2165 (2012)

25. Salimi, P, Latif, A, Hussain, N: Modified $\alpha-\psi$-contractive mappings with applications. Fixed Point Theory Appl. 2013 Article ID 151 (2013)

26. Karapinar, E, Samet, B: Generalized $(\alpha-\psi)$ contractive type mappings and related fixed point theorems with applications. Abstr. Appl. Anal. 2012, Article ID 793486 (2012)

27. Karapinar, E, Kumam, P, Salimi, P: On $\alpha$ - $\psi$-Meir-Keeler contractive mappings. Fixed Point Theory Appl. 2013, Article ID 94 (2013)

28. Ran, ACM, Reurings, MCB: A fixed point theorem in partially ordered sets and some applications to matrix equations. Proc. Am. Math. Soc. 132, 1435-1443 (2003)

29. Agarwal, RP, El-Gebeily, MA, O’Regan, D: Generalized contractions in partially ordered metric spaces. Appl. Anal. 87, 109-116 (2008)

30. Bhaskar, TG, Lakshmikantham, V: Fixed point theorems in partially ordered metric spaces and applications. Nonlinear Anal. 65, 1379-1393 (2006)

31. Ćirić, L, Abbas, M, Saadati, R, Hussain, N: Common fixed points of almost generalized contractive mappings in ordered metric spaces. Appl. Math. Comput. 217, 5784-5789 (2011)

32. Hussain, N, Khan, AR, Agarwal, RP: Krasnosel'skii and Ky Fan type fixed point theorems in ordered Banach spaces. J. Nonlinear Convex Anal. 11(3), 475-489 (2010)

33. Hussain, N, Kadelburg, Z, Radenovic, S, Al-Solamy, FR: Comparison functions and fixed point results in partial metric spaces. Abstr. Appl. Anal. 2012, Article ID 605781 (2012)

34. Dung, NV, Hang, VTL: Fixed point theorems for weak C-contractions in partially ordered 2-metric spaces. Fixed Point Theory Appl. 2013, Article ID 161 (2013)

35. Agarwal, RP, Hussain, N, Taoudi, MA: Fixed point theorems in ordered Banach spaces and applications to nonlinear integral equations. Abstr. Appl. Anal. 2012, Article ID 245872 (2012)

36. Hussain, N, Taoudi, MA: Krasnosel'skii-type fixed point theorems with applications to Volterra integral equations. Fixed Point Theory Appl. 2013, Article ID 196 (2013)

10.1186/1687-1812-2014-6

Cite this article as: Fathollahi et al.: Fixed point results for modified weak and rational $\alpha$ - $\psi$-contractions in ordered

2-metric spaces. Fixed Point Theory and Applications 2014, 2014:6

\section{Submit your manuscript to a SpringerOpen ${ }^{\circ}$ journal and benefit from:}

- Convenient online submission

Rigorous peer review

- Immediate publication on acceptance

- Open access: articles freely available online

- High visibility within the field

- Retaining the copyright to your article

Submit your next manuscript at $>$ springeropen.com 